\title{
Biologia floral e fenologia reprodutiva de Schinus terebinthifolius Raddi (Anacardiaceae) em Restinga do Norte Fluminense
}

\author{
Lorena Farizel Cesário ${ }^{1}$ e Maria Cristina Gaglianone ${ }^{1}$
}

Recebido em 17/04/2007. Aceito em 13/11/2007

\begin{abstract}
RESUMO - (Biologia floral e fenologia reprodutiva de Schinus terebinthifolius Raddi (Anacardiaceae) em restinga do Norte Fluminense). A fenologia reprodutiva, a morfologia floral e o sistema reprodutivo de Schinus terebinthifolius foram investigados em duas fisionomias de vegetação da restinga de Grussaí/Iquipari, Rio de Janeiro, no período de janeiro a dezembro/2004. Schinus terebinthifolius apresentou estratégia de florescimento do tipo cornucópia, com dois picos de floração ao ano na estação chuvosa, e frutificou no período seco. A análise morfológica das flores e os experimentos de polinização confirmaram que esta espécie é dióica e apresenta reprodução xenógama obrigatória. Ocorreu alta sincronia entre plantas masculinas e femininas, considerada importante estratégia para espécies dióicas. Não houve diferença entre a frutificação por polinização natural e polinização cruzada, nem entre as duas fitosionomias estudadas, sendo os valores encontrados menores do que os observados em outros trabalhos.
\end{abstract}

Palavras-chave: Restinga, morfologia floral, aroeira, dioicia, xenogamia

ABSTRACT - (Floral biology and reproductive phenology of Schinus terebinthifolius Raddi (Anacardiaceae) in the restinga of northern Rio de Janeiro State). Reproductive phenology, floral morphology and the reproductive system of Schinus terebinthifolius were investigated in two physiognomies of restinga vegetation at Grussai/Iquipari, Rio de Janeiro, from January to December/2004. Schinus terebinthifolius had cornucopia flowering strategy, with two flowering peaks during the year, both in the rainy season; fruit was set in the dry period. Morphological analysis of the flowers and pollination experiments confirmed dioicism and obligatory xenogamy in this species. High synchrony between male and female plants occurred, an important strategy for dioecious species. No difference in fruit set was found between natural and cross pollinations in the two physiognomies studied, indicating lower values than those observed in others studies.

Key words: Restinga, floral morphology, Brazilian-pepper, dioicism, xenogamy

\section{Introdução}

Estudos fenológicos procuram discutir como eventos biológicos repetitivos, tais como floração e frutificação, estão relacionados com a sazonalidade climática e as interações ecológicas (Frankie et al. 1974). Assim, estes estudos são considerados essenciais para se entender a regeneração e reprodução das plantas (Talora \& Morellato 2000). Considerando que o período reprodutivo é uma fase importante para a dinâmica populacional, a identificação de padrões fenológicos de floração e frutificação é importante também como subsídio para planos de manejo e conservação de espécies vegetais.

A dioicia é um sistema sexual observado em $6 \%$ das espécies de Angiospermas (Renner \& Rickfles 1995), e caracterizado pela separação completa das funções sexuais em indivíduos produtores de flores exclusivamente estaminadas ou pistiladas (Tanurdzic \& Banks
2004). Como conseqüência desta separação sexual, flores estaminadas (masculinas) e pistiladas (femininas) apresentam características sexuais secundárias, como diferenças de tamanho e atratividade, consideradas como estratégias adaptativas para possibilitar o fluxo direcional de pólen a estigmas coespecíficos (Grant 1995). A dioicia provavelmente evoluiu várias vezes dentro das Angiospermas, sendo a redução de endogamia, a especialização sexual (alocação de recursos em indivíduos masculinos e femininos) e a seleção disruptiva, considerados os principais fatores responsáveis pela evolução deste sistema reprodutivo (Bawa 1980).

Schinus terebinthifolius Raddi (Anacardiaceae), conhecida como aroeira ou aroeira-vermelha, é espécie dióica que apresenta ampla distribuição geográfica e plasticidade ecológica (Lorenzi 1998). A ela são atribuídas propriedades medicinais (Amorim \& Santos 2003) e alimentícias, pois seus frutos ("pimenta-rosa") são apreciados como condimento alimentar na cozinha

\footnotetext{
1 Universidade Estadual do Norte Fluminense Darcy Ribeiro, Laboratório de Ciências Ambientais, Av. Alberto Lamego 2000, Campos dos Goytacazes, 28015-602 Rio de Janeiro, RJ, Brasil

2 Autor para correspondência: lorena@yahoo.com.br; mcrisgag@uenf.br
} 
nacional e internacional, sendo muito explorados em áreas de restinga, inclusive no Norte Fluminense. A espécie também se destaca na recuperação de áreas degradadas (Souza et al. 2001) e em programas de reflorestamento (Kageyama \& Gandara 2000). É uma espécie muito procurada por aves, possivelmente dispersoras de seus frutos (Souza et al. 2001; Guimarães 2003), que são do tipo drupa, pequenos, numerosos, vermelhos e brilhantes quando maduros (Lorenzi 1998).

$\mathrm{Na}$ restinga de Grussaí/Iquipari Schinus terebinthifolius é considerada importante pelo alto índice de cobertura vegetal, ocorrendo em três das quatro formações vegetacionais da área: formação praial com moitas, formação de Clusia e mata de restinga (Assumpção \& Nascimento 2000). As fitofisionomias praial com moitas e mata de restinga diferem entre si com relação às condições microclimáticas (maior salinidade e ventos mais fortes na área de moitas) e à composição florística. Nesta área, S. terebinthifolius ocorre em moitas arredondadas, de porte sub-arbustivo, podendo ocorrer em moitas mistas com Eugenia sulcata Spreng. Na formação Mata de Restinga, onde a diversidade florística é maior e o porte da vegetação mais alto, S. terebinthifolius ocorre na forma de pequenas árvores ou arbustos e normalmente associada a várias outras espécies (Assumpção \& Nascimento 2000).

A exploração da aroeira-vermelha na restinga de Grussaí/Iquipari para extração dos frutos, principalmente na formação praial com moitas, mais acessível à população, tem se tornado uma fonte de renda importante para os moradores, em períodos de menor atividade pesqueira. Devido a esta crescente exploração, estudos sobre esta espécie são importantes, já que não se conhecem os seus polinizadores, o potencial de produção de frutos da área, nem tampouco o impacto desta extração na polinização e frutificação da aroeira. Os objetivos deste trabalho são descrever a fenologia reprodutiva, a morfologia floral e o sistema reprodutivo de S. terebinthifolius em restinga na região norte do Rio de Janeiro.

\section{Material e métodos}

Local de estudo - A restinga de Grussaí/Iquipari está localizada no município de São João da Barra (RJ) ( $\left.21^{\circ} 44^{\prime} \mathrm{S} ; 41^{\circ} 02^{\prime} \mathrm{W}\right)$. Esta formação difere das demais descritas para o Rio de Janeiro, devido à ausência de duna, grande extensão da formação de praia e baixa similaridade de espécies vegetais com outras restingas da região. Assim, a restinga de Grussaí/Iquipari pode ser considerada um elemento distinto no mosaico formado pelas restingas do Norte Fluminense (Assumpção \& Nascimento 2000). O solo da região é caracterizado como areias quartzosas marinhas associadas a podzol hidromórfico de origem flúviomarinha (RadamBrasil 1983). A região apresenta clima tropical sub-úmido a semi-árido. A precipitação pluviométrica média anual varia de 800 a $1.200 \mathrm{~mm}$, com as maiores taxas de precipitação nos meses de verão, e as menores no inverno (Fig. 1). O vento predominante tem a direção nordeste e atinge as maiores velocidades nos meses de agosto a dezembro (RadamBrasil 1983).

$\mathrm{O}$ estudo foi realizado de janeiro a dezembro de 2004, em duas unidades fitofisionômicas distintas nesta restinga. A Formação Praial com Moitas ocorre entre 250-580 m na direção mar-interior, zona onde aparecem as primeiras moitas de arbustos, sendo coberta por espécies psamófilas. A Formação Mata de Restinga inicia aos 980 m na direção mar-interior, onde o adensamento das moitas forma uma mata contínua (Assumpção \& Nascimento 2000).

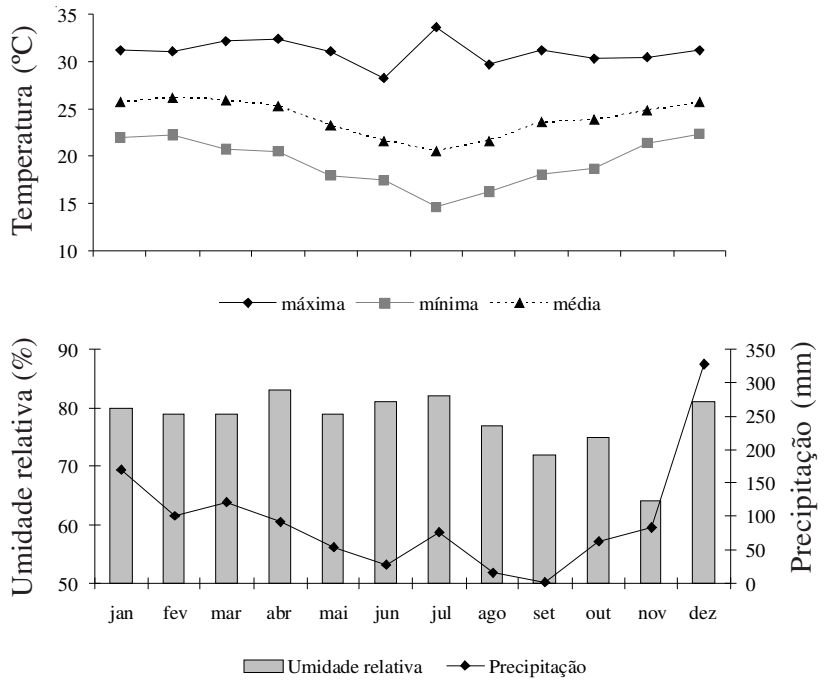

Figura 1. Diagrama climático referente ao período de janeiro a dezembro/2004 da Estação Climatológica Principal de Campos dos Goytacazes, RJ, Brasil.

Fenologia reprodutiva - A fenologia de floração e frutificação foi avaliada mensalmente através de dois parâmetros: estimativa da porcentagem de indivíduos em floração e intensidade de floração e frutificação. A estimativa da porcentagem de indivíduos em floração foi avaliada em 80 indivíduos encontrados ao longo de trilhas em cada fitofisionomia. Os indivíduos encontrados foram avaliados quanto à presença ou ausência de flores ou botões. As intensidades de floração e de frutificação foram avaliadas em indivíduos de $S$. terebinthifolius marcados com placas de alumínio numeradas e de tamanho similar. A intensidade de floração foi avaliada em 40 indivíduos por fitofisionomia (20 masculinos e 20 femininos) e a intensidade de frutificação em 20 
indivíduos femininos de cada fitofisionomia. A intensidade destas fenofases foi quantificada pela metodologia de Fournier (1974), que considera cinco categorias de intensidade, sendo calculada pela equação: $\left[\%\right.$ Fournier $=\left(\sum\right.$ Fournier $\left.\left./ 4 \mathrm{~N}\right) \times 100\right]$, onde $\Sigma$ Fournier $=$ somatório das categorias de Fournier para cada indivíduo e $\mathrm{N}$ = número de indivíduos da amostra. As categorias de intensidade de Fournier são: (1) ausência da fenofase (floração ou frutificação), (2) presença da fenofase entre 1 e $25 \%$, (3) presença da fenofase entre 26 e $50 \%$, (4) presença da fenofase entre 51 e $75 \%$ e (5) presença da fenofase entre 76 e $100 \%$.

$O$ índice de sincronia de floração $(Z)$ foi calculado (cf. Augspurger 1983) para toda a população, entre indivíduos masculinos e femininos e entre áreas de moita e mata de restinga. A sincronia para a fenofase de floração (Xi) foi medida individualmente para 56 plantas, somando o número de meses em que houve sobreposição da fenofase entre determinado indivíduo e o restante da amostra, baseado na seguinte fórmula (Augspurger 1983): $\left[\mathrm{Xi}=\sum_{\mathrm{n}} \mathrm{ej} /(\mathrm{N}-1)\right.$ fi $]$, onde ej é o número de meses em que os indivíduos i e j floresceram sincronicamente, com i diferente de j; fi é o número de meses que o indivíduo i floresceu; N é o número total de indivíduos da amostra. $\mathrm{O}$ índice de sincronia da espécie $(\mathrm{Z})$ é calculado pela média aritmética de Xi, como: $\mathrm{Z}=\sum \mathrm{Xi} / \mathrm{N}$. Este índice varia de zero (ausência de sincronia) a um (sincronia perfeita, ou seja, a floração de todos os indivíduos da espécie teria ocorrido no mesmo período durante o ano). Análise de correlação de Spearman foi utilizada para verificar associação entre as fenofases reprodutivas e as variáveis climáticas (umidade relativa, precipitação, temperatura média) nas duas fitofisionomias, através do programa R-system versão 2.2.1.

Morfologia floral - Para estudos de morfologia floral, amostras de flores de S. terebinthifolius em diferentes fases de antese foram coletadas no campo, fixadas em FAA (5\% formol 40\%: 5\% ácido acético glacial: 90\% etanol 30\%) e medidas em laboratório sob microscópio estereoscópico. As medidas tomadas foram diâmetro da corola, comprimento das anteras e diâmetro do ovário. Diferenças destas medidas entre flores masculinas, femininas e hermafroditas foram testadas através de análise de variância de uma via seguida do teste de Tukey, utilizando o programa R-system versão 2.2.1. Anteras dos diferentes tipos morfológicos foram lavadas em álcool $70 \%$ e o seu conteúdo polínico montado em lâminas com gelatina-fucsina (Dafni 1992), para verificação da presença de grãos de pólen em microscopia óptica (400x).

Sistema reprodutivo - Para testar a ocorrência de autopolinização espontânea, apomixia e xenogamia, botões em pré-antese de flores funcionalmente femininas ou masculinas foram isolados com sacos de papel semipermeável. Para verificar a ocorrência de apomixia, foram retiradas as anteras (emasculação), atrofiadas nas flores femininas. A xenogamia foi verificada através do tratamento de polinização manual cruzada. $\mathrm{O}$ pólen de flores funcionalmente masculinas foi transferido manualmente para os estigmas de flores funcionalmente femininas; o contrário não foi feito, pois as anteras das flores femininas não continham pólen. As flores polinizadas manualmente foram novamente ensacadas, para impedir contatos posteriores com polinizadores. Adicionalmente, flores em antese foram marcadas com fita colorida e deixadas sob condições naturais de polinização para observar o desenvolvimento de frutos. Diferenças da proporção de frutos formados entre as fitofisionomias foram testadas através do teste do $\chi^{2}$ (Arango 2001).

\section{Resultados}

Schinus terebinthifolius apresentou dois picos de floração durante o ano, ambos na estação chuvosa (Fig. 2). A produção de botões apresentou picos em março e dezembro. Esta fenofase foi positivamente correlacionada com a precipitação $\left(r_{s}=0,69, p=0,014\right.$; $\left.\mathrm{r}_{\mathrm{s}}=0,76, \mathrm{p}=0,054\right)$ e com a temperatura média mensal $\left(r_{s}=0,76, p=0,006 ; r_{s}=0,85, p=0,011\right)$ nas áreas de moitas e mata, respectivamente. A fenofase de floração não apresentou correlação significativa com nenhuma variável climática analisada. A fenofase de frutificação apresentou maior intensidade entre abril e julho, no período seco; esta fenofase não apresentou correlação com as variáveis climáticas.

O índice de sincronia de floração para a população de Grussaí/Iquipari de $S$. terebinthifolius foi $\mathrm{Z}=0,75$; entre as plantas femininas foi de $Z=0,76$ e entre as masculinas foi de $Z=0,73$. Os valores de $Z$, quando analisadas separadamente as áreas de moitas e de mata de restinga, foram 0,80 e 0,82 respectivamente, indicando que a sincronia entre os indivíduos de mesma formação vegetacional é um pouco maior do que entre indivíduos do mesmo sexo.

As flores de $S$. terebinthifolius são pentâmeras, actinomorfas, pequenas (Tab. 1), dialissépalas e dialipétalas, dispostas em inflorescências compostas do tipo panícula racemosa. As sépalas são pequenas e verdes, de formato triangular, e as pétalas são pequenas, brancas e ovais. Possuem dez estames heterodínamos, dispostos em duas fileiras concêntricas. As anteras são basifixas e apresentam deiscência longitudinal. O tecido que forma a teca é branco e o pólen é amarelo. As flores femininas possuem um estigma trilobado, ovário súpero e unilocular. A análise em microscopia óptica de 67 anteras 
de tamanhos diferentes, extraídas de botões florais $(\mathrm{n}=31)$ de plantas femininas $(\mathrm{n}=7)$, revelou que nenhuma delas apresentava grãos de pólen.

Schinus terebinthifolius apresentou plantas com flores estaminadas e gineceu muito reduzido, e plantas com flores pistiladas e estames reduzidos (Tab. 1, Fig. 3). Foram observados também alguns indivíduos na população (aproximadamente $2 \%$ ) que, embora apresentando flores estaminadas apresentavam frutos
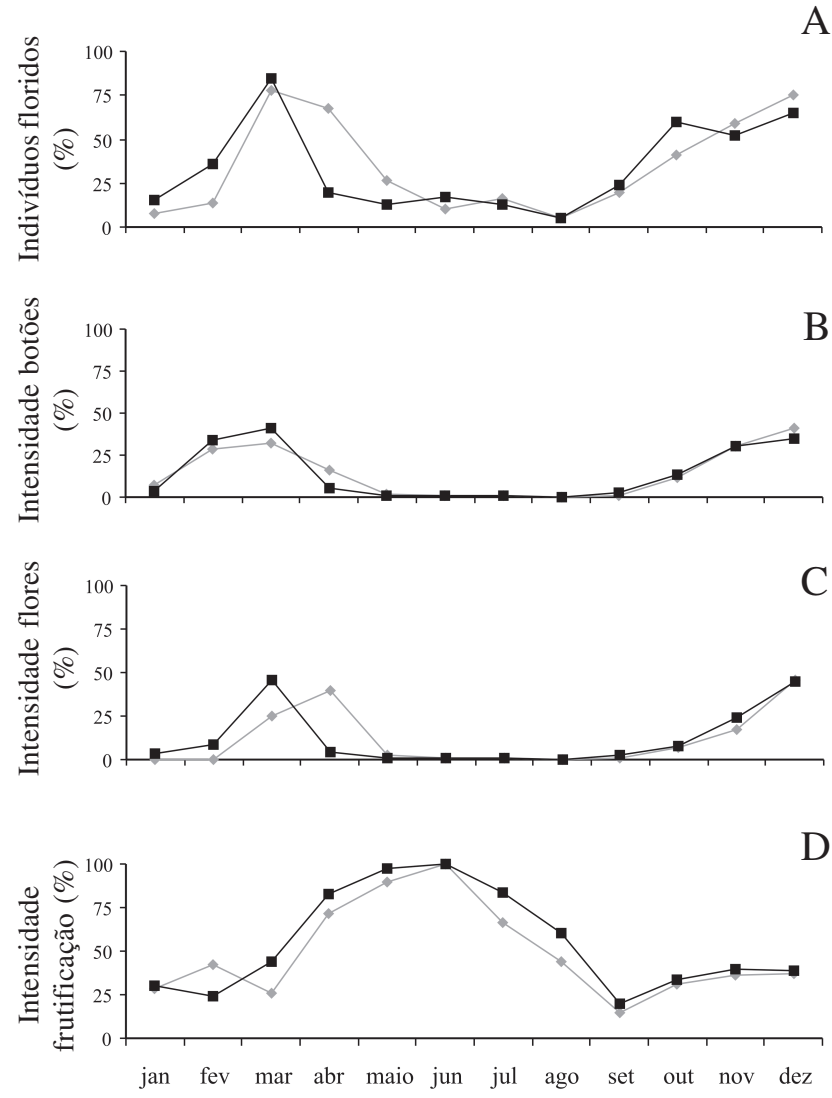

Figura 2. Fenologia reprodutiva de Schinus terebinthifolius Raddi (Anacardiaceae) nas formações Praial com moitas (linhas cinzas) e mata de restinga (linhas pretas) na restinga de Grussaí/Iquipari, São João da Barra, RJ, Brasil. (A) Porcentagem de indivíduos floridos, (B) Intensidade de floração, indicada pelo índice de Fournier para \% de botões, (C): Intensidade de floração, indicada pelo índice de Fournier para \% de flores abertas, (D): Intensidade de frutificação.

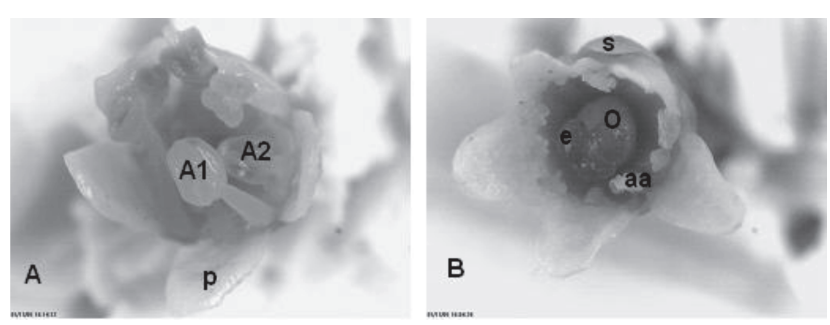

Figura 3. Flores estaminada (A) e pistilada (B) de Schinus terebinthifolius Raddi (Anacardiaceae). A1 = antera maior; $\mathrm{A} 2=$ antera menor; aa = antera atrofiada; e = lobo do estigma; o = ovário; $\mathrm{p}=$ pétala; $\mathrm{s}=$ sépala.

bem formados. As medidas das flores estaminadas dessas plantas hermafroditas não diferiram das medidas de flores estaminadas de plantas masculinas (Tab. 1). A formação de frutos nestes indivíduos, no entanto, não foi acompanhada, não sendo verificado se resultavam de flores funcionalmente femininas ou bissexuais; estes indivíduos foram considerados hermafroditos. A proporção de frutos formados variou entre os tratamentos de polinização natural e manual cruzada nas fitofisionomias praial com moitas $\left(\chi^{2}=2,58, \mathrm{gl}=1\right.$, $\mathrm{p}=0,01)$ e mata de restinga $\left(\chi^{2}=1,26, \mathrm{gl}=1, \mathrm{p}=0,01\right) ;$ no entanto, estas diferenças não foram estatisticamente significativas (Tab. 2). Não foi detectada agamospermia.

\section{Discussão}

Schinus terebinthifolius apresentou dois períodos distintos de maior floração em um mesmo ano, durante a estação quente e chuvosa, quando a temperatura e precipitação atingiram seus maiores valores, e frutificou no período seco. Este padrão coincide com o evidenciado por Talora \& Morelatto (2000) para muitas espécies arbóreas da floresta de restinga na região sudeste. Segundo estes autores, o início de floração estaria correlacionado ao aumento da temperatura e comprimento do dia, enquanto que a frutificação teria correlação negativa com estes fatores. Para S. terebinthifolius, a correlação entre a fenofase de botões e temperatura foi confirmada.

Tabela 1. Médias (desvio padrão) de quatro medidas ( $\mathrm{mm}$ ) de flores pistiladas e estaminadas de Schinus terebinthifolius (Anacardiaceae) na restinga de Grussaí/Iquipari, São João da Barra, RJ, Brasil. Médias na mesma linha seguidas da mesma letra não diferem estatisticamente $(\mathrm{p}<0,0001)$

\begin{tabular}{lcccc}
\hline & $\begin{array}{c}\text { Flores estaminadas de } \\
\text { plantas masculinas }\end{array}$ & $\begin{array}{c}\text { Flores pistiladas de } \\
\text { plantas femininas }\end{array}$ & $\begin{array}{c}\text { Flores estaminadas de } \\
\text { plantas hermafroditas }\end{array}$ & $\begin{array}{c}\text { Valor de F / } \\
\text { Graus de liberdade }\end{array}$ \\
\hline Diâmetro da corola & $3,75 \pm 0,35 \mathrm{~A}$ & $2,36 \pm 0,36 \mathrm{~B}$ & $3,56 \pm 0,37 \mathrm{~A}$ & $122,82 / 127$ \\
Comprimento das anteras maiores & $2,41 \pm 0,16 \mathrm{~A}$ & $0,85 \pm 0,03 \mathrm{~B}$ & $2,45 \pm 0,09 \mathrm{~A}$ & $3168,4 / 127$ \\
Comprimento das anteras menores & $1,24 \pm 0,075 \mathrm{~A}$ & $0,66 \pm 0,01 \mathrm{~B}$ & $1,21 \pm 0,06 \mathrm{~A}$ & $1494,7 / 127$ \\
Diâmetro do ovário & $0,56 \pm 0,075 \mathrm{~A}$ & $1,18 \pm 0,18 \mathrm{~B}$ & $0,57 \pm 0,08 \mathrm{~A}$ & $358,95 / 127$ \\
$\mathrm{~N}^{\circ}$ flores (n $\mathrm{n}^{\circ}$ de plantas) & $50(5)$ & $50(5)$ & $30(3)$ & \\
\hline
\end{tabular}


Tabela 2. Resultados dos experimentos sobre o sistema reprodutivo de Schinus terebinthifolius (Anacardiaceae) na formação praial com moitas e na mata de restinga em Grussaí/Iquipari, São João da Barra, RJ, Brasil. AE = autopolinização espontânea, A = apomixia, PN = polinização natural, $\mathrm{PC}=$ polinização cruzada manual.

\begin{tabular}{|c|c|c|c|c|c|c|c|}
\hline & \multirow[b]{2}{*}{ Tratamento } & \multicolumn{3}{|c|}{ Flores femininas } & \multicolumn{3}{|c|}{ Flores masculinas } \\
\hline & & $\mathrm{N}$ flores & $\mathrm{N}$ frutos & $\%$ frutificação & $\mathrm{N}$ flores & $\mathrm{N}$ frutos & $\%$ frutificação \\
\hline \multirow[t]{4}{*}{ Formação praial com moitas } & $\mathrm{AE}$ & 127 & 0 & 0 & 175 & 0 & 0 \\
\hline & A & 93 & 0 & 0 & 94 & 0 & 0 \\
\hline & PN & 908 & 255 & 28 & 758 & 0 & 0 \\
\hline & $\mathrm{PC}$ & 49 & 9 & 18,4 & 0 & 0 & 0 \\
\hline \multirow[t]{4}{*}{ Formação mata de restinga } & $\mathrm{AE}$ & 45 & 0 & 0 & 73 & 0 & 0 \\
\hline & A & 30 & 0 & 0 & 46 & 0 & 0 \\
\hline & $\mathrm{PN}$ & 100 & 23 & 23 & 242 & 0 & 0 \\
\hline & PC & 30 & 5 & 16,6 & 0 & 0 & 0 \\
\hline
\end{tabular}

O padrão de florescimento de $S$. terebinthifolius pode ser considerado sub-anual (sensu Newstrom \& Frankie 1994) por apresentar mais de um ciclo de florescimento por ano. Esta espécie produz grande quantidade de flores por um longo período, com picos de florescimento durante o verão. Este padrão é semelhante ao tipo cornucópia (sensu Gentry 1974), verificado também em outras famílias neotropicais, como Malvaceae (Gaglianone 2000).

A sincronia de florescimento entre plantas femininas e masculinas é fator imprescindível para o sucesso da polinização de espécies dióicas. De acordo com Rathcke $\&$ Lacey (1985), uma maior sincronia pode ser vantajosa por aumentar a atratividade de polinizadores; porém pode também atrair florívoros, como Coleoptera observados principalmente em flores masculinas de S. terebinthifolius (obs. pessoal). Outra desvantagem seria o menor movimento inter-plantas dos polinizadores, que podem rapidamente saciar-se, devido à abundância de recursos (Augspurger 1981; Rathcke \& Lacey 1985). Para S. terebinthifolius, isto talvez seja compensado pela pequena quantidade de pólen e néctar oferecido por flor.

A análise morfológica das flores de $S$. terebinthifolius e os experimentos de polinização confirmam que esta espécie é funcionalmente dióica, como já apontado por outros autores. A ocorrência de indivíduos hermafroditas em populações desta espécie, evidenciada neste trabalho, já havia sido sugerida por Ewel et al. (1982), na Flórida. Este parece ser um fenômeno pouco freqüente, não tendo sido citado por outros autores que estudaram a espécie em locais distintos no Brasil (Lenzi \& Orth 2004a; b).

As flores de $S$. terebinthifolius apresentam corola aberta, permitindo fácil acesso aos diferentes visitantes florais. Segundo Richards (1986), flores com esta característica atraem muitos visitantes não especializados, como observado para Schinus terebinthifolius (obs. pessoais). Características florais como corola actinomorfa, coloração pálida das pétalas, antese diurna e oferta de pólen e néctar, permitem considerar esta espécie como entomófila (Faegri \& Pij1 1979). Além disso, S. terebinthifolius é considerada neste trabalho como uma fonte importante de pólen e néctar para a entomofauna da restinga por ser uma espécie abundante e devido a sua morfologia floral simples, permitindo a utilização de seus recursos por um amplo espectro de visitantes.

Os testes para detecção do sistema reprodutivo de $S$. terebinthifolius demonstram que a estratégia de polinização é cruzada, confirmando a necessidade de insetos para o transporte do pólen. A taxa de frutificação de $S$. terebinthifolius sob condições naturais observada neste estudo, é baixa quando comparada a outro estudo (45\% observada por Lenzi \& Orth 2004b).

Os resultados deste estudo demonstram que S. terebinthifolius é espécie dióica, generalista e entomófila. A semelhança entre flores masculinas e femininas, aliada à sincronia de floração entre os sexos, parece contribuir para seu sucesso reprodutivo, através da atração de visitantes florais a plantas masculinas e femininas. A baixa frutificação de $S$. terebinthifolius resultante de polinização natural sugere que a supressão da vegetação nativa devido à urbanização causa o declínio de polinizadores da aroeira e que a conservação da restinga de Grussaí/Iquipari é essencial para a manutenção dos polinizadores desta espécie.

\section{Agradecimentos}

Ao Laboratório de Ciências Ambientais da Universidade Estadual do Norte Fluminense Darcy Ribeiro (UENF), pelo apoio logístico e concessão da bolsa PIBIC/UENF à primeira autora; à FAPERJ, pelos recursos financeiros (Proc. E-26/171.622/02); ao José Louvise Gomes Júnior, pela confecção das fotografias 
das flores; ao José Vanderley Degel e Heuzenil de Souza, pelo auxílio nas coletas de campo; à Ana Moreira, responsável pela Estação Climatológica Principal de Campos dos Goytacazes, por fornecer os dados climáticos.

\section{Referências bibliográficas}

Amorim, M.M.R. \& Santos, L.C. 2003. Tratamento de vaginose bacteriana com gel vaginal de Aroeira (Schinus terebinthifolius Raddi): ensaio clínico randomizado. Revista Brasileira de Ginecologia e Obstetrícia 25: 95-102.

Arango, H.G. 2001. Bioestatística Teórica e Computacional. Rio de Janeiro, Ed. Guanabara Koogan.

Assumpção, J. \& Nascimento, M.T. 2000. Estrutura e composição florística de quatro formações vegetais de restinga no complexo lagunar Grussaí/Iquipari, São João da Barra, R.J, Brasil. Acta Botanica Brasilica 14: 301-315.

Augspurger, C.K. 1981. Reproductive synchrony of a tropical shrub: experimental studies on effects of pollinators and seed predators on Hybanthus prunifolius (Violaceae). Ecology 62: 775-788.

Augspurger, C.K. 1983. Phenology, flowering synchrony, and fruit set of six Neotropical shrubs. Biotropica 15: 257-267.

Bawa, K.S. 1980. Evolution of dioecy in flowering plants. Annual Review of Ecology and Systematic 11: 15-39.

Dafni, A. 1992. Pollination ecology: a practical approach. Oxford University.

Ewel, J.J.; Ojima, D.S.; Karl, D.A. \& Debusk, W.F. 1982. Schinus in sucessional ecosystems of Everglades National Park. USA, National Park Service, South Florida Research Center, Everglades National Park, Homestead.

Faegri, K. \& Pijl, L. 1979. The principles of pollination ecology. 3 ed. London, Pergamon Press

Fournier, L.A. 1974. Un método cuantitativo para la medición de características fenológicas en árboles. Turrialba 24: 422-423.

Frankie, W.G.; Baker, H.G. \& Opler, P.A. 1974. Comparative phenological studies of trees in tropical wet and dry forests in the lowlands of Costa Rica. Journal of Ecology 62: 881-919.

Gaglianone, M.C. 2000. Biologia floral de espécies simpátricas de Malvaceae e suas abelhas visitantes. Biociências 8: 13-31.

Gentry, A.H. 1974. Flowering phenology and diversity in tropical Bignoniaceae. Biotropica 6: 64-68.
Grant, V. 1995. Sexual selection in plants: pros and cons. Proceedings of the National of Sciences of the United States of America 92: 1247-1250.

Guimarães, M.A. 2003. Frugivoria por aves em Tapirira guianensis (Anacardiaceae) na zona urbana do município de Araruama, estado do Rio de Janeiro, sudeste brasileiro. Atualidades Ornitológicas 116: 12-22.

Kageyama, P.Y. \& Gandara, F.B. 2000. Recuperação de áreas ciliares. Pp. 249-269. In: R.R. Rodrigues \& H. Leitão Filho (org.). Matas Ciliares: Conservação e Recuperação. São Paulo, EDUSP.

Lenzi, M. \& Orth, A.I. 2004a. Fenologia reprodutiva, morfologia e biologia floral de Schinus terebinthifolius Raddi (Anacardiaceae), em restinga da ilha de Santa Catarina, Brasil. Biotemas 17: 67-89.

Lenzi, M. \& Orth, A.I. 2004b. Caracterização funcional do sistema reprodutivo da aroeira-vermelha (Schinus terebinthifolius Raddi), em Florianópolis-SC, Brasil. Revista Brasileira de Fruticultura 26: $198-201$.

Lorenzi, H. 1998. Árvores brasileiras: manual de identificação e cultivo de plantas arbóreas nativas do Brasil. v.1. São Paulo, Ed. Plantarum.

Newstrom, L.E. \& Frankie, G.W. 1994. A new classification for plant phenology based on flowering patterns in Lowland Tropical Rain Forest trees at La Selva, Costa Rica. Biotropica 26: 141-159.

RadamBrasil. 1983. Rio de Janeiro/Vitória; Geologia, Geomorfologia, Pedologia, Vegetação e Uso Potencial da Terra - SF.23/24. Projeto RADAMBRASIL, Rio de Janeiro.

Rathcke, B. \& Lacey, E.P. 1985. Phenological patterns of terrestrial plants. Annual Review of Ecology and Systematics 16: 179-214.

Renner, S.S. \& Ricklefs, R.E. 1995. Dioecy and its correlates in the flowering plants. American Journal of Botany 82: 596-606.

Richards, A.J. 1986. Plant breeding systems. London, Cambridge University Press.

Souza, P.A.; Venturini, N.; Macedo, R.L.G.; Alvarenga, M.I.N. \& da Silva, V.F. 2001. Estabelecimento de espécies arbóreas em recuperação de área degradada pela extração de areia. Cerne 7: 43-52.

Talora, D.C. \& Morelatto, P.C. 2000. Fenologia de espécies arbóreas em floresta de planície litorânea do sudeste do Brasil. Revista Brasileira de Botânica 23: 13-26.

Tanurdzic, M. \& Banks, J.A. 2004. Sex-determining mechanisms in land plants. The Plant Cell 16: 61-71. 